right ovary there was a bleeding point from a small adhesion, which had apparently held the ovary down to Douglas's pouch antil the growing uterus had stretched it, and it then got torn some hours before the operation. I secured this adhesion with a ligature, and, there being no further bleeding point, the abdomen was closed. She made an uninterruptedly good recovery, and her pregnancy continued till the ninth month, when it was terminated by Dr. Housem in owing to accidental benorrhage. The child was born alive.

CASE 4.-On Ang. 29th Dr. Limont of Newcastle asked me to see with him a lady twenty-seven years of age, two months pregnant for the first time, who was suffering interse pin from a small ovarian tumour on her right side. I remored the tumour (about the size of a hen's egg), and the patient made an excellent recovery. At the end of a month she went for a fortnight to Bournemouth, where she unfortunately contracted a very severe attack of bronchitis, after which she suffered from albuminuria with considerable ciema of the legs, and on Feb. 15th she gave birth to a dead child. Since then the albumen has disappeared, and she is now quite well.

The above cases, baing recent ones, are recorded to show that abdominal section can be safely done during pregnancy, a question which has been a good deal discussed in this country and in Germany during the past year. My own experience in a larze number of cases of abdominal surgery and general surgery, such as amputations, removal of breasts, \&c., is that it is very unusual for an operation to terminate pregnancy.

sunderland.

\section{NOTE ON THE TREATMENT OF DIPHTHERIA.}

By G. HUNTRR MACKENZIE, M.D. EDIX.,

SURGEOY FOR DISEASES OF THE THROAT AND NOSE TO THE EYE, EAR, AXD THROAT IXFIRMARY, EDIXBURGII.

THE marked success which apparently follows the treatment of diphtheria by antitoxin raises the question whether the action of this remedy can be expedited or assisted by any anxiliary treatment, and, if so, what are the means which can so assist? In cases in which the disease has extended to the larynz, with consequent more or less obstruction to the respiration, it appears to be essential to recovery that some mechanical means should be adopted to maintain the integrity of the respiratory passage until the antitoxin has bad time, possibly by repeated injections, to act. Roux ${ }^{1}$ affirms that under the influence of antitoxin the false membrane ceases to grow within twenty-four hours from the first injection, and detaches itself in from thirty-six to forty-eight bours, at the latest by the third day. The thesis I now wish to maintain is that in intubation or tubage the medical man has a safe, easy, and eff 3 ctive mans of combating the conditions attendant upon impeded respiration, which the new system of treatment occasionally requires. In fifteen cases of intubation in diphtheria reported in detail by $\mathrm{me}^{2}$ the average length of time during which the tube lay in the larynx was twenty-six hours, and several of the patients who died succumbed to other causes than respiratory impediment. If the patient can b3 tided over twenty-four hours by means of an operation which does not require the administra. tion of an anæsthetic and is not accompanied or followed by hwmorrhage or shock, and if antitoxin be simultaneously administered, the remedy is allowed time to commence to act under the most favourable conditions. If, on the other hand, marked obstruction of the larynx has developed before the commencement of administration of the antitoxin, and if no special means be adopted to combat it, the patient may die, and, judging from sorne reports of cases which have appeared in the medical pres3, has died before be could be thoromghly brought under the inflaence of the remedy. From a fairly extensive experience of both tracheotomy and intubation in diphtheria I feel warranted in agreeing with Rou in the following expression of opinion. He says in the article previonsly referred to: "How many children may be spared tracheotomy if the serum were administered sooner? We can even say that with the use of serum tracheotomy should, in the gront mijority of cases, be replaced by tabage. It is now no longer a question of leaving a tube in the Jarynx for days; it will sullice moro frequently to retain it during twenty-four or forty-eight hours to prevent imminent asphy xia, and to gain time until the false membranes detach themselves. Tubage is the complement of the serum treatment of the futuro, tracheotomy will be the exception, and greatly to the benefit of the children." ('The italics are mine.) But even if alonger period than from twenty-four to forty-eight hours be necessary to allow the therapentic effect of the antitoxin to develop it can be afforded by intubation, as the following cases show.

CAsE 1.-On April 19th, 1897, I was asked by Dr. Thyne of $\mathrm{E}$ dinburgh to meet him in consultation in the case of a boy aged six years, the subject of diphtheria. Membrano had been seen on the tonsils and adjoining parts of the pharynx, and had subsequently extended to the larynx. We found him in extremis, and as the boy's father positively refused to permit of tracheotomy being porformed, it was suggested that intubation might be tried. This was accordingly done. The anxiliary treatment consisted in the administration of small hourly doses of mercury, and of a mixture of strophanthus and strychnice, with free alcoholic stimulation. The tabe was permanently withdrawn on the fifreenth dxy. The patient recovered after a tedious convalescence.

CASE 2.-On June 15th, 1894, I was called by Dr. Hamilton Wylie of Pilrig to see a girl aged seven year, reported to be suffering from diphtheria, with great difficulty in breathing. Intubation was performed. The auxiliary treatment was on similar lines to that of Case 1 . The tube was withdrawn on the tenth day. The patient recovered, with post diphtheritic manifestations during convalescence.

I may observe that I have never witnessed a patient in a worse plight than the child was in Case 1 before the performance of intubation. What struck the attendant phyzicians and myself in regard to the results of intubation in these cases were: (1) the great and instantaneous relief which followed insertion, and in Case 1 re-insertion, of the tabe; (2) the easy manner in which it was borne by the little patients, and the absence of annoyance to them from its use ; (3) no difficalty in swallowing whilst the tabe was in situ in the larynx; and (4) the tube in each instance could easily have been retained for a longer period if such had been considered necessary. There seem to be gocd grounds for believing that intubation or tubage is a valuable auxiliary in the antitoxin treatment of diphtheria, and that the day is fast approaching when it will supersede tracheotomy- "greatly," as Roux observes, "to the bentfit of the children.'

Edinburgh.

\section{Clinitial llates:}

\section{MEDICAL, SURGICAL, OBSTETRICAL, AND} THERAPEUTICAL.

\section{A FATAL CASE OF ANOREXIA NERVOSA.}

By C. F. Marshall, M.D. ViCT., F.R.C.S. ENG ,

LATE SCRGICAL REGISTRAR AXD AYASTHETIST TO THE HOSPITAL FOR SICK CIILDREN, GREA'I ORMOXD-STREET, W.C.

IN connexion with fatal cases of anorexia nerrosa, an interesting example of which appeared in THE LANCET of Jan. 5th, 1895, it may be of interest to record another case of this affection which was under my care in 1890. The history is briefly as follows :-

A girl, said to be eleven years of age, but who looked nearly fourteen years old, was admitted to the North Eastern Children's Hospital on May 10tb, 1890. 'The history was only of one week's loss of flesh, anorexia, and vomiting. Four years previously she was said to have had similar attacks. $\mathrm{O} n$ examination she was found to be extremely cmaciated, but there were no signs of organic disease. She had a wild, hysterical appearance, was very restless, and refused all food; her bodily strength, however, was greater than would be supposed from her extreme emaciation. (The abdomen was so sunken that the vertebral column and sacrum could be easily felt.) As she refused all food she was fed on enemata of peptonised milk beef tea, and brandy. In 